\title{
Cerium-Iron Oxide Catalyzed Photodegradation of Brilliant Blue G
}

\author{
NEEMA PAPNAI and K. L. AMETA* \\ Department of Chemistry, FASC, Mody University of Science and Technology, \\ Lakshmangarh-332311, Rajasthan, India \\ klameta77@hotmail.com
}

Received 20 February 2014 / Accepted 26 February 2014

\begin{abstract}
Cerium-Iron oxide nanoparticles were synthesized by co-precipitation method and used as photocatalyst for the decolorization of Brilliant Blue $\mathrm{G}$ dye under visible light. Absorption studies were carried out at different $\mathrm{pH}$ and catalyst dosages at different light intensities to assess their effect on the rate of photocatalytic decolorization. The decolorization was dependent on $\mathrm{pH}$, dye concentration, catalyst loading and light intensity.
\end{abstract}

Keywords: Cerium-Iron oxide, Brilliant Blue G, Photocatalyst, Dye decolorization

\section{Introduction}

Dyes enhance our environment, bringing color into our lives by their wide use in textiles, paper, plastics, leather, food and cosmetic industry. At present more than 10,000 dyes have been effectively commercialized ${ }^{1-3}$. Synthetic dyes are a major group of dyes that have wide application in textile industry because of their ease of synthesis, versatility and cost effectiveness ${ }^{4,5}$. However other than important class of synthetic organic compounds, they are also common industrial pollutants. They may enter in the environment during production or later during textile dyeing processes, ${ }^{6,7}$. A major source of release of color into the environment is associated with the incomplete exhaustion of dyes onto textile fibre from an aqueous dyeing process. Therefore, the need to reduce the amount of residual dye in textile effluent has become a major concern in recent years ${ }^{8,9}$.

Most of these dyes are chemically stable and are difficult to remove from wastewater as they are stable to light, heat and oxidizing agents ${ }^{10,11}$, causing environmental concern because of their color, biorecalcitrance, potential toxicity and carcinogenicity to animals and human beings ${ }^{12}$.

Thus, there is an urgent need to develop effective methods to treat these toxic textile effluents. A number of technologies such as electro-chemical precipitation, bio-absorption/ bio-oxidation, ozonation, membrane separation processes, physico-chemical treatment, chemical oxidation are available for decolorization ${ }^{5,13}$. Photocatalytic decolorization is an alternative method to other conventional physicochemical and biological methods to treat dye effluent at low cost and less time ${ }^{14}$. 
The present study was aimed at the synthesis of innovative light sensitive Cerium-Iron oxide $\left(\mathrm{CeFeO}_{3}\right)$ nanoparticles for decolorization of Brilliant Blue $\mathrm{G}$ dye, which is being used extensively in textile industry.

\section{Experimental}

The synthesis of mixed Cerium-Iron oxide was achieved by co-precipitation method. For this $0.1 \mathrm{M}$ solution of both $\mathrm{Ce}\left(\mathrm{NO}_{3}\right)_{3} \cdot 6 \mathrm{H}_{2} \mathrm{O}$ and $\mathrm{Fe}\left(\mathrm{NO}_{3}\right)_{3} \cdot 9 \mathrm{H}_{2} \mathrm{O}$ were mixed and aqueous solution of $1 \mathrm{M} \mathrm{NaOH}$ was added slowly to the mixed nitrate solutions at room temperature with concurrent vigorous stirring, on which a brown colored precipitate was formed. The $\mathrm{pH}$ of the mixed solution was adjusted at different $\mathrm{pH}$ but at $\mathrm{pH} 10$ complete precipitation was observed. After 4 hours of continuous stirring, the precipitate was filtered and repeatedly washed with deionized water. The precipitate was kept in an oven at $110^{\circ} \mathrm{C}$ for drying and then grounded in acetone using a pastel and mortar. The powder material was then subjected to calcination at $500{ }^{\circ} \mathrm{C}$ for 4 hours in muffle furnace under static air.

\section{$X R D$ characterization of the synthesized mixed cerium-iron oxide}

The prepared mixed oxide was characterized by x-ray powder diffraction method to establish the phase purity and crystallinity by x-ray diffractometer. The crystallite size was determined by Scherrer equation.

\section{Photocatalytic decolorization of Brilliant Blue $G$ dye}

A stock solution of Brilliant Blue $\mathrm{G}$ of $1.0 \times 10^{-3} \mathrm{M}$ concentration was prepared by dissolving $0.854 \mathrm{~g}$ of Brilliant Blue $\mathrm{G}$ in $1000 \mathrm{~mL}$ of double distilled water. The absorption maximum of the dye was determined with the help of a UV-VIS spectrophotometer (Systronics Model 106). The maximum absorption of Brilliant Blue G was found at $570 \mathrm{~nm}$. Photocatalytic decolorization of Brilliant Blue $\mathrm{G}$ was studied by taking $50 \mathrm{~mL}$ reaction mixture which contains $5.0 \times 10^{-5} \mathrm{M}$ of Brilliant Blue $\mathrm{G}$ and $0.05 \mathrm{~g}$ of Cerium-Iron oxide. The reaction mixture was exposed to light. For irradiation purpose, $200 \mathrm{~W}$ tungsten lamp (Philips) was used. The intensity of light was measured by solar power meter (TENMARS Model TM 207). A water filter was used to cut off thermal radiation. The desired $\mathrm{pH}$ of the solution was adjusted by the addition of $0.1 \mathrm{~N}$ sodium hydroxide and $0.1 \mathrm{~N}$ hydrochloric acid solutions. To measure the rate of decolorization, optical density was taken at regular time intervals.

\section{Results and Discussion}

\section{Characterization of the synthesized nanoparticles}

The XRD pattern for Cerium-Iron oxide is shown in Figure 1. Graph has been plotted between intensity (cycles per second) and $2 \theta$ values (in degrees). The nanoparticles size was $23.28 \mathrm{~nm}$ as determined by Scherrer's equation.

\section{Photocatalytic decolorization of dye}

A $2.0 \mathrm{~mL}$ of the solution was taken out from the reaction mixture at regular time intervals and absorbance was measured. It was observed that the absorbance of the solution decreases with increasing time intervals showing thereby that the concentration of the dye decreases with increasing time of exposure. A plot of $1+\log$ O.D. versus time was linear and follows first order kinetics. The rate constant was determined by using the expression, $k=2.303 \mathrm{x}$ slope. The typical run for dye decolorization is given in Table 1 and graphically represented in Figure 2. 


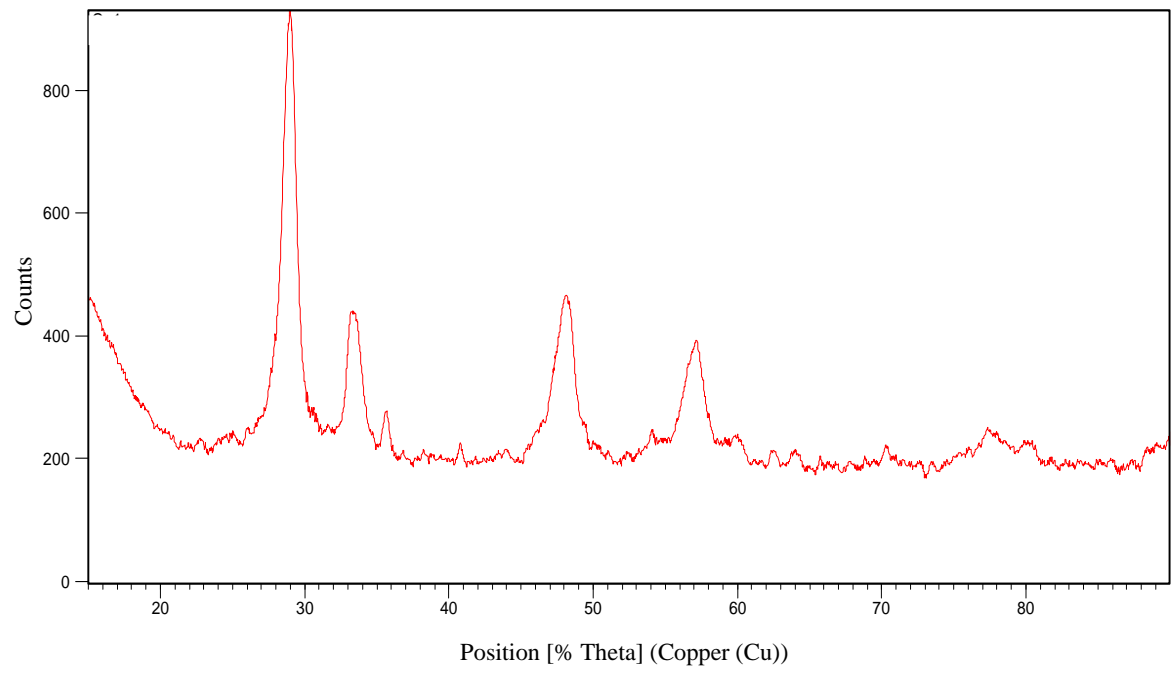

Figure 1. Powder x-ray diffraction pattern of cerium-iron oxide

Table 1. Typical run for decolorization of Brilliant Blue $\mathrm{G}$ using $\mathrm{CeFeO}_{3}{ }^{*}$

\begin{tabular}{ccc}
\hline Time, min & Optical density (O.D.) & 1+log O.D. \\
\hline 0 & 0.625 & 0.79588 \\
20 & 0.549 & 0.73961 \\
40 & 0.493 & 0.69284 \\
60 & 0.441 & 0.64443 \\
80 & 0.405 & 0.60745 \\
100 & 0.367 & 0.56467 \\
120 & 0.322 & 0.50786 \\
140 & 0.288 & 0.45939 \\
& $\mathrm{k}=8.96 \times 10^{-5} \mathrm{~s}^{-1}$ & \\
\hline
\end{tabular}

${ }^{*}$ Reaction Conditions: Dye concentration $=5 \times 10^{-5} \mathrm{M}$, Light intensity $=600 \mathrm{Wm}^{-2}, \mathrm{CeFeO}_{3}=0.07 \mathrm{~g} / 50$ $m L$ dye solution, $p H=2.5$

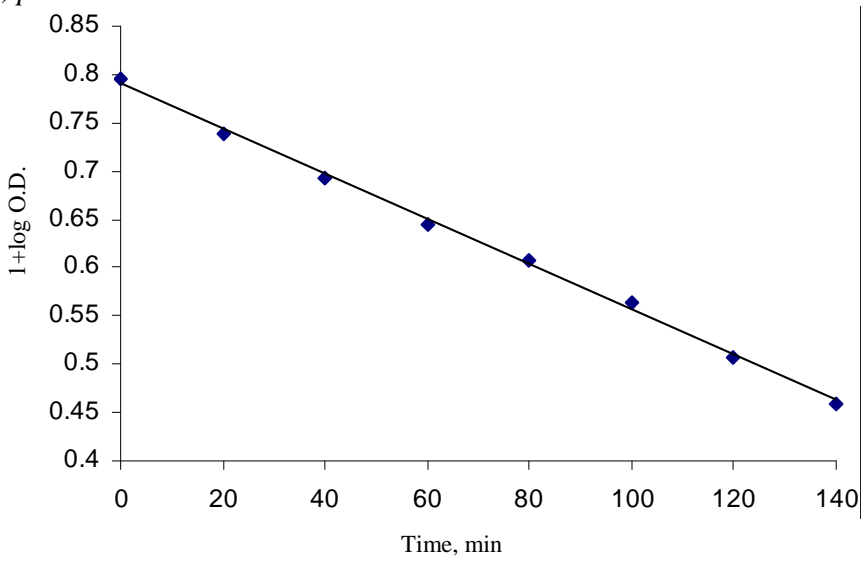

Figure 2. Plot of $1+\log$ O.D. verses time for a typical run 


\section{Effect of different variables on photocatalytic decolorization of dye}

\section{Effect of $p H$}

The $\mathrm{pH}$ of the solution is likely to affect the decolorization of dye and hence, the effect of $\mathrm{pH}$ on the rate of decolorization of the dye was investigated in the $\mathrm{pH}$ range 2.5 to 8.0 (Table 2). Maximum reaction rate was observed at $\mathrm{pH} 2.5$. However, a further increase in $\mathrm{pH}$ of solution resulted in decreased reaction rate. The decolorization is mainly attributed to the variation of surface charge properties of the photocatalyst at different $\mathrm{pH}$ values.

Table 2. Effect of $\mathrm{pH}$ on rate of decolorization of Brilliant Blue $\mathrm{G}^{*}$

\begin{tabular}{cc}
\hline $\mathrm{pH}$ & $\mathrm{k} \times 105 \mathrm{~s}^{-1}$ \\
\hline 2.5 & 8.96 \\
3.0 & 6.37 \\
3.5 & 4.46 \\
4.0 & 2.82 \\
4.5 & 2.43 \\
5.0 & 2.27 \\
5.5 & 2.05 \\
6.0 & 1.86 \\
6.5 & 1.72 \\
7.0 & 1.64 \\
7.5 & 1.39 \\
8.0 & 1.08 \\
\hline
\end{tabular}

${ }^{*}$ Reaction Conditions: Dye Concentration $=5 \times 10^{-5} \mathrm{M}$, Light intensity $=600 \mathrm{Wm}^{-2}, \mathrm{CeFeO}_{3}=0.07 \mathrm{~g} /$ $50 \mathrm{~mL}$ dye solution.

\section{Effect of dye concentration}

The effect of dye concentration on the rate of the reaction was studied by taking different concentrations of dye. The results are reported in Table 3. It was observed that the rate of photocatalytic decolorization increases with an increase in the concentration of the dye up to $5.0 \times 10^{-5} \mathrm{M}$. On further increasing the concentration of dye, the rate of photocatalytic bleaching decreases. It may be due to the fact that as the concentration of dye was increased, more dye molecules were available for excitation and energy transfer and, hence an increase in the rate of decolorization but on further increase of dye concentration, dye starts acting as a filter for the incident light and will not permit the light intensity to reach the semiconductor surface and as a result rate of decolorization decreases.

Table 3. Effect of dye concentration on rate of decolorization of Brilliant Blue $\mathrm{G}^{*}$

\begin{tabular}{cc}
\hline [brilliant Blue G] $\times 10^{-5} \mathrm{M}$ & $\mathrm{K} \times 10^{5} \mathrm{~s}^{-1}$ \\
\hline 4.5 & 8.33 \\
5.0 & 8.96 \\
5.5 & 7.89 \\
6.0 & 7.05 \\
6.5 & 6.24 \\
7.0 & 5.03 \\
7.5 & 4.12 \\
\hline
\end{tabular}

*Reaction Conditions: $\mathrm{CeFeO}_{3}=0.07 \mathrm{~g} / 50 \mathrm{~mL}$ dye solution, $\mathrm{pH}=2.5$, Light intensity $=600 \mathrm{Wm}^{-2}$. 


\section{Effect of catalyst loading}

The amount of catalyst is also likely to affect the rate of photocatalytic decolorization of dyes and therefore, different amount of Cerium-Iron oxide $\left(\mathrm{CeFeO}_{3}\right)$ nanoparticles were taken. Results (Table 4) shows that an increase in catalyst amount from $0.01 \mathrm{~g}$ to $0.07 \mathrm{~g}$ increased the photo decolorization efficiency, as the exposed surface area of the semiconductor also increases and further increase in catalyst above $0.07 \mathrm{~g}$ has negligible effect on the rate of decolorization.

Table 4. Effect of amount of nanoparticle on the rate of decolorization of Brilliant Blue $\mathrm{G}^{*}$

\begin{tabular}{cc}
\hline $\mathrm{CeFeO}_{3}(\mathrm{~g} / 50 \mathrm{~mL}$ dye solution $)$ & $\mathrm{k} \times 10^{5} \mathrm{~s}^{-1}$ \\
\hline 0.02 & 5.57 \\
0.03 & 5.92 \\
0.04 & 6.41 \\
0.05 & 6.89 \\
0.06 & 7.63 \\
0.07 & 8.96 \\
0.08 & 8.09 \\
0.09 & 7.85 \\
0.10 & 7.51 \\
\hline
\end{tabular}

* Reaction Conditions: Dye Concentration $=5 \times 10^{-5} \mathrm{M}$, Light intensity $=600 \mathrm{Wm}^{-2}, p H=2.5$.

\section{Effect of light intensity}

The effect of light intensity on the rate of the reaction is summarized in Table 5. It has been observed that on increasing the intensity of light up to $600 \mathrm{Wm}^{-2}$, the rate of reaction also increases because on increasing the light intensity, the number of photons striking per unit area of reaction mixture will also increase. This will result in a corresponding increase in the rate of decolorization of Brilliant Blue G. Small decrease in the rate of decolorization on further increasing light intensity may be due to some thermal or side reactions.

Table 5. Effect of light intensity on the rate of decolorization of Brilliant Blue G

\begin{tabular}{cc}
\hline Light intensity $\left(\mathrm{Wm}^{-2}\right)$ & $\mathrm{k} \times 10^{5} \mathrm{~s}^{-1}$ \\
\hline 200 & 6066 \\
300 & 7.35 \\
400 & 7.42 \\
500 & 7.88 \\
600 & 8.96 \\
700 & 7.99 \\
800 & 7.55 \\
\hline
\end{tabular}

${ }^{*}$ Reaction Conditions: Dye Concentration $=5 \times 10^{-5} \mathrm{M}, \mathrm{CeFeO}_{3}=0.07 \mathrm{~g} / 50 \mathrm{~mL}$ dye solution, $\mathrm{pH}=2.5$.

\section{Mechanism}

On the basis of these observations, a tentative mechanism for photocatalytic decolorization of Brilliant Blue $\mathrm{G}$ may be proposed as -

$$
\begin{gathered}
{ }^{1} B B_{0} \stackrel{h v}{\longrightarrow}{ }^{1} B B_{1} \\
{ }^{1} B B_{1} \stackrel{I S C}{\longrightarrow}{ }^{3} B B_{1} \\
\mathrm{SC} \stackrel{\mathrm{hv}}{\longrightarrow} \mathrm{e}^{-}(\mathrm{CB})+\mathrm{h}^{+}(\mathrm{VB}) \\
e^{-}+\mathrm{O}_{2} \longrightarrow \mathrm{O}_{2}^{-}
\end{gathered}
$$




$$
\begin{gathered}
\mathrm{O}_{2}^{-\cdot}+{ }^{3} \mathrm{BB}_{1} \longrightarrow \text { Leuco BB } \\
\text { Leuсо BB } \longrightarrow \text { Products }
\end{gathered}
$$

Brilliant Blue $\mathrm{G}(\mathrm{BB})$ absorbs radiations of suitable wavelength and gives rise to its first excited singlet state. Then it undergoes intersystem crossing (ISC) to give the triplet state of the dye. On the other hand, the semiconducting Cerium-Iron oxide (SC) also utilizes the radiant energy to excite its electron from valence band to the conduction band. This electron will be abstracted by oxygen molecule (dissolved oxygen) generating superoxide anion radical $\left(\mathrm{O}_{2}^{-}\right)$. This anion radical will reduce the dye Brilliant Blue $\mathrm{G}$ to its leuco form, which may ultimately degrade to products. It was also confirmed that this decolorization proceeds through reduction and not oxidation as the rate of decolorization was not affected appreciably in presence of hydroxyl radical scavenger (2-propanol).

\section{Conclusion}

The present study reveals the ability of the Cerium-Iron oxide nanoparticles to decolorize Brilliant Blue G. The method of synthesis of Cerium-Iron oxide nanoparticles and dye decolorization technique may be employed effectively in the treatment of textile dye effluent. In current study it was found that decolorization is dependent on the $\mathrm{pH}$, dye concentration, catalyst dosage and light intensity. The optimal values of $\mathrm{pH}$, dye concentration, catalyst dosage and light intensity for decolorization were found at $\mathrm{pH} 2.5,5 \times 10^{-5} \mathrm{M}, 0.07 \mathrm{~g}$ Cerium-Iron oxide/ $50 \mathrm{~mL}$ dye solution and $600 \mathrm{Wm}^{-2}$ respectively. As Cerium-Iron oxide possess potential to degrade dye (Brilliant Blue $\mathrm{G}$ ), therefore may serve as a potent dye decolorizing agent.

\section{Acknowledgment}

The authors are thankful to Dean, FASC, Mody University of Science and Technology for constant encouragement during this work.

\section{References}

1. Chen K C, Haug W T, Wu T Y and Houng J Y, J Ind Microbiol Biotechnol., 1999, 23, 686-690.

2. $\quad$ Malik P K, Dyes and Pigments. 2003, 56(3), 239-249;

DOI:10.1016/S0143-7208(02)00159-6

3. $\quad$ Leena R and Selva Raj D, Afr J Biotechnol., 2008, 7(18), 3309-3313.

4. Raju N S, Venkataramana G V, Girisha S T, Vinay B. Raghavendra and Shivashankar P. J Appl Sci.. 2007, 7(2), 298-301.

5. $\quad$ Dogan M and Alkan M, Chemosphere, 2003, 50(4), 517-528;

DOI:10.1016/S0045-6535(02)00629-X

6. $\quad$ Ali H and Muhammad S K, Afr J Biotechnol., 2008, 7(6), 831-833.

7. Olukanni O D, Osuntoki A A and Gbenle G O, Afr J Biotechnol., 2006, 5, 1980-1984.

8. Vaidya A A and Datye K V, Colourage, 1982, 29(1), 3-10.

9. $\quad$ Pang Y L and Abdullah A Z, CLEAN-Soil, Air, Water, 2013, 41(8), 751-764.

10. Nassar M M and Magdy H Y, Chem Eng J., 1997, 66(3), 223-226; DOI:10.1016/S1385-8947(96)03193-2

11. Robinson T, McMullan G, Marchant R and Nigam P, Bioresour Technol., 2001, 77(3), 247-255; DOI:10.1016/S0960-8524(00)00080-8

12. Siddiqui M F, Andleeb S, Ali N, Ghumro P B and Ahmed S, Afr J Biotechnol., 2009, 8(20), 5570-5577.

13. Adinew B, Chem Bulgarian J Sci Edu., 2012, 21(3), 434-456.

14. Pignatelloo J J, Oliveros E and Mackay A, Environ Sci Technol., 2006, 36, 1-84; DOI:10.1080/10643380500326564 